\title{
The Pursuit of a HIV Vaccine - Trials, Challenges and Strategies
}

\section{Nageswara Rao Alla*}

Department of Pulmonary Allergy and Critical Care medicine, Department of Medicine, University of Pittsburgh, Pittsburgh, USA

\begin{abstract}
The search for a HIV vaccine that can elicit potent, long lasting and broad immune responses to both prevent acquisition of infection and control viral replication has been going on for over two decades. The modest success of the RV144 vaccine efficacy trial and isolation of broadly neutralizing antibodies capable of neutralizing different HIV strains has reinvigorated research in antibody based vaccine design and development strategies. This review will discuss the efficacy trials conducted to date, lessons learned from the trials, challenges and current strategies being pursued in the HIV vaccine field.
\end{abstract}

Keywords: HIV; Vaccine; Antibodies; Clinical trials

\section{Introduction}

The trademark of a viral vaccine is to elicit robust, effective and extensive immune responses against the virus. One way of demonstrating that antibodies can elicit protection is by passive administration followed by virus challenge in in vivo models. A vaccine capable of eliciting satisfactory levels of antibody against HIV-1 could prevent the establishment of infection. In the case of HIV-1 the development of an effective vaccine has been an elusive one mainly due to the antigenic and genetic diversity of the virus. The first endeavor to produce a protective vaccine against HIV-1 was to generate HIV-1 Envelope (Env)-specific antibody responses using recombinant gp120 antigens indicated that the antibodies failed to neutralize HIV-1 [1]. Two more studies in Phase III efficacy clinical trials revealed the failure of the recombinant gp 120 vaccine to prevent HIV-1 infection or reduce viremia $[2,3]$. Studies following these trials based on eliciting cytotoxic T Cell (CTL) responses against HIV did not show any promise. But lately, the modest efficacy against HIV shown in the RV144 Phase III clinical trial in controlling HIV infection [4] and the isolation of neutralizing antibodies $(\mathrm{nAb})$ called broadly neutralizing antibodies (bnAb) able to neutralize a broad spectrum of HIV-1 variants [5] has generated great optimism in the HIV-1 vaccine research field. In this review we will discuss the existing status of the research efforts focused on the development of an HIV-1 vaccine, lessons learned, challenges to be addressed and current strategies to develop an effective vaccine.

\section{Clinical Trials}

The development of an HIV vaccine is a crucial component required to bring the HIV/AIDS epidemic to an end. Vaccines can be either therapeutic or prophylactic. Therapeutic vaccines are designed to control/clear HIV from already infected individuals whereas prophylactic or preventive vaccines are designed to reduce the risk of infection in people who are not infected with HIV and also to reduce the viral load set point in people infected with HIV. Most of the research has been focused on the development of a preventive vaccine. Here we will discuss the phase IIb/III efficacy trials of preventive vaccines. More than two hundred trials have been conducted to date to develop an effective vaccine of which only 6 trials reached Phase IIb or III stages (Table 1). VAX003 and VAX004 trials tested HIV vaccine named AIDSVAX a vaccine consisting B envelope of recombinant gp120 protein. The vaccine was designed to elicit antibody response against HIV gp120. Phase I and Phase II trials of the original version showed excellent safety in chimpanzees and elicited production of antibodies in $99 \%$ of human volunteers leading to initiation of the first Phase
III clinical trials in 1998. Both trials were randomized, double-blind, placebo-controlled efficacy trials of a bivalent recombinant glycoprotein $120[3,6]$. VAX003 was conducted in Bangkok and Thailand with 2400 volunteers and VAX004 was conducted in North America and Europe with 5400 volunteers $[3,6]$. Both trials showed no effect for prevention of acquisition of HIV infection and ended in 2003 [3,6]. In 2005 STEP/ HVTN502 trial a phase IIb, randomized, double-blind, placebocontrolled study with 3000 HIV seronegative high-risk volunteers was initiated. The vaccine used in the study MRKAd5 HIV-1 gag/pol/nef is a replication-defective adenovirus type 5 (Ad5) vector vaccine [7]. The study was halted in 2007 when it showed no efficacy in protection from HIV infection but surprisingly showed modest increase in HIV infection in Ad5-seropositive uncircumcised men [7]. The Phambili/ HVTN 503 study tested the same Merck Ad5 HIV-1 vaccine in South Africa. The Phambili study was also halted in 2007 with only 800 volunteers recruited after the STEP study results became available. Similar to what was observed in the STEP study there was no effect of the vaccine in preventing HIV infection [8]. Vaccine tested in the STEP and Phambili trials were designed to induce cell mediated immune response. The RV144 efficacy trial with 16,402 volunteers started in 2003 was conducted in Thailand and the results were reported in 2009. The candidate vaccine evaluated in this trial was a combination of two vaccines one ALVAC-HIV (a recombinant canarypox vector vaccine) as prime injection and two AIDSVAX B/E (a recombinant gp120) as booster injection. This combination vaccine strategy was designed to induce antibody and cell mediated immune response. This is the only trial which showed a modest efficacy of $31.2 \%$ in reducing the risk of HIV infection but did not show any effect in decreasing viremia in HIV infected individuals [4]. The HVTN 505 trial is a phase IIb study which started in 2009 with 2504 volunteers to test the efficacy of a combination of two vaccines designed to induce antibody and cell mediated immune response. One a recombinant DNA based priming vaccine and two a recombinant Ad5 based boosting vaccine. The trial was discontinued in 2013 as an interim review revealed that the vaccine did not prevent HIV

*Corresponding author: Nageswara Rao Alla, Division of Pulmonary, Allergy and Critical Care Medicine, University of Pittsburgh, Pittsburgh, Pennsylvania, PA -15213, USA, Tel: 267467 5439; E-mail: allanagesh@gmail.com

Received March 04, 2014; Accepted April 11, 2014; Published April 25, 2014

Citation: Nageswara Rao A (2014) The Pursuit of a HIV Vaccine - Trials, Challenges and Strategies. J AIDS Clin Res 5: 298. doi:10.4172/2155-6113.1000298

Copyright: (c) 2014 Nageswara Rao A. This is an open-access article distributed under the terms of the Creative Commons Attribution License, which permits unrestricted use, distribution, and reproduction in any medium, provided the original author and source are credited. 


\begin{tabular}{|c|c|c|c|c|c|c|c|c|c|c|}
\hline TRIAL & PRODUCT & CLADE & CANDIDATE & START & END & COUNTRIES & \begin{tabular}{|c|} 
NUMBER OF \\
VOLUNTEERS
\end{tabular} & PHASE & $\begin{array}{c}\text { IMMUNE } \\
\text { RESPONSE }\end{array}$ & RESULT \\
\hline VAX003 & AIDSVAX & $B / E$ & $\begin{array}{l}\text { Recombinant gp120 } \\
\text { Protein }\end{array}$ & 1998 & 2003 & $\begin{array}{c}\text { Canada, Netherlands, Puerto } \\
\text { Rico, US }\end{array}$ & 5,417 & III & $\begin{array}{c}\text { T cell, } \\
\text { Antibodies }\end{array}$ & No Efficacy \\
\hline VAX004 & AIDSVAX & $B / E$ & $\begin{array}{l}\text { Recombinant gp120 } \\
\text { Protein }\end{array}$ & 1998 & 2003 & Thailand & 2,546 & III & $\begin{array}{c}\text { T cell, } \\
\text { Antibodies }\end{array}$ & No Efficacy \\
\hline STEP & MRK-Ad5 & $\mathrm{B}$ & gag/pol/nef & 2005 & 2007 & $\begin{array}{c}\text { Australia, Brazil, Canada, } \\
\text { Dominican Republic, Haiti, } \\
\text { Jamaica, Peru, Puerto Rico, } \\
\text { USA }\end{array}$ & 3,000 & $\mathrm{Ilb}$ & T cell & No Efficacy \\
\hline PHAMBILI & MRK-Ad5 & $\mathrm{B}$ & Ad5 gag/pol/nef & 2005 & 2007 & South Africa & 801 & $\mathrm{Ilb}$ & T cell & No Efficacy \\
\hline RV144 & $\begin{array}{c}\text { ALVAC-HIV and } \\
\text { AIDSVAX }\end{array}$ & $\mathrm{B} / \mathrm{E}$ & $\begin{array}{c}\text { Recombinant gp120 } \\
\text { Protein + Canary pox } \\
\text { vector }\end{array}$ & 2003 & 2009 & Thailand & 16,402 & III & $\begin{array}{c}\text { T cell, } \\
\text { Antibodies }\end{array}$ & $31.20 \%$ \\
\hline HVTN 505 & DNA and Ad5 & $\mathrm{A} / \mathrm{B} / \mathrm{C}$ & $\begin{array}{c}\text { DNAAd5 gag/pol/ } \\
\text { nef }\end{array}$ & 2009 & 2013 & USA & 2,500 & $\mathrm{Ilb}$ & $\begin{array}{c}\text { T cell, } \\
\text { Antibodies }\end{array}$ & No Efficacy \\
\hline
\end{tabular}

Table 1: Synopsis of completed Phase IIb/III efficacy trials of HIV vaccine.

infection nor did it decrease the viremia in HIV infected individuals. The modest efficacy of RV144 trial has led to follow up studies to understand why the RV144 vaccine regimen worked and apply the same criteria for development of a better, more efficient vaccine.

\section{Lessons Learned and Clinical Trials Underway}

Even though HVTN 503 and 502 trials of the MRKAd5 HIV-1 vaccine failed, the studies indicated that the non-human primate (NHP) simian-human immunodeficiency virus (SHIV) challenge model with prevailing SHIVs is ambiguous and imperfect to assess cytotoxic $\mathrm{T}$ cell (CTL)-based vaccines. In contrast the Simian Immunodeficiency Virus (SIV) challenge model better predicted the failure to reduce viremia, was unsuccessful in explaining acquisition of infection results $[9,10]$ underscoring the need for better NHP models. These trials also indicated that conducting smaller efficacy trials may generate better and effective evidence to guide prospective trials [11]. Furthermore the trials showed the importance of testing the immunity to vectors (Example: Ad5) [10].

The RV144 trial was the only vaccine to show a modest effect and of the subsequent post hoc analysis done revealed a lot of useful information. It is important to note that the RV144 trial result indicates that developing a vaccine to prevent HIV infection is possible. In addition to that, RV144 has offered a unique opportunity to comprehensively search for immune correlates of risk of infection. This will provide a wealth of information to help reveal the immune responses necessary for protection against HIV infection. Researchers at U.S. Military HIV Research Program (MHRP) and National Institute of Allergy and Infectious Diseases (NIAID) have discovered that individuals producing relatively high levels of a specific immunoglobulin G (IgG) antibody that binds to the first and second variable regions, or V1V2 of the HIV Env protein had better protection against HIV infection compared to those who did not produce high levels of the antibody [12]. Vaccinated individuals producing relatively high levels of immunoglobulin A (IgA) antibody that attaches to first constant region or $\mathrm{C} 1$ of the HIV Env protein did not benefit from this vaccination [12]. Genomic studies of HIV sequences from 110 participants from the RV144 trials also corroborated that antibodies are being targeted towards V1V2 [13]. A study also reported that the efficacy of the vaccine peaks around 12 months and gradually decreases indicating a requirement for a booster dose to enhance the immune response [14]. Most importantly a recent study has shown that the same antibodies induced by the vaccine decrease the risk of infection by different clades or subtypes of HIV i.e. A, B, C and AE [15]. Follow-up clinical studies RV305 and RV306 are underway to determine the efficacy of multiple booster doses of the same vaccine as RV144 and to acquire more immunogenicity data (www.avac.org/report2012). It is imperative to know if the results from RV144 trial and follow up studies can be applied to other types of vaccine candidates and against distinct routes of exposure to the virus (mucosal or systemic). Therefore, more research is needed to answer these questions [16].

\section{Challenges Involved in the Design and Development of HIV Vaccine}

- Massive diversity and variability of HIV presents a huge challenge to an efficacious vaccine design, as the vaccine needs to protect against a plethora of different strains of the virus circulating around the globe [17]. The vaccines studied to date are designed against one or two types of HIV clades.

- High level of difficulty in generating a vaccine that can activate CD4+ T cells. .

- Eliciting robust cellular and humoral immune response against a broad range of HIV subtypes

- Lack of a human model showing complete recovery from HIV infection and an appropriate animal model to predict the potency of an HIV vaccine. This makes it difficult to identify and induce immune responses required to cure HIV infection [16]. This is supported by the failure of VAX004 and VAX003 trials as the vaccine candidates were tested prior in NHPs

- Lack of structural details of immunogens/antigens. Inability to make antigens that mimic the conformation of the natural epitope.

- Non neutralizing antibodies interfering with protective response of the broadly neutralizing antibodies (bnAbs). Immune correlates of the RV144 trial have shown production of Non neutralizing antibodies

- Person to person variability in T-cell and antibody responses induced by the vaccine candidates [18]. This was revealed from the study of Immune correlates of the clinical trials

- Designing an antigen binding to the B-Cell Receptor (BCR) with high affinity. Accessibility of epitopes to antibodies [16].

- Study of the immune correlates of the vaccine trial indicates it is important to stimulate the production of both IgA and IgG antibodies.

- Clearance of latent virus. None of the trials have been shown to effectively clear the latent viruses. 


\section{Designs and Strategies for HIV Vaccine}

\section{Attenuated and killed virus vaccines}

These vaccines rely on direct mimicking of the viral infection and have been tested in NHPs. None of these approaches induced neutralizing antibody responses and hence did not advance to human trials [19]. Setback of these vaccines is the risk of reversal to pathogenic forms also poses safety concerns [20].

\section{Recombinant protein subunit vaccines}

These are subunits of HIV surface proteins, example gp120 and gp160, made using recombinant DNA technology. AIDSVAX used in the VAX003 and VAX004 trials was based on recombinant gp120 (rgp120). The failure of the rgp120 based vaccine caused researchers to focus on developing soluble, recombinant Env trimers as antigens which resemble the functional HIV Env spike [20]. Lately, a soluble trimer that closely mimics antigenic properties of the natural Env trimer has been developed and shown to induce enhanced neutralizing antibody responses relative to monomers in guinea pigs [21].

Discovery of broadly neutralizing antibodies (bnAbs) against HIV-1 with high potency had significant consequences in vaccine design. bnAbs namely PG9, PG16 and 10E8 showed neutralization breadth ranging from $80-98 \%$ [22-24]. The bnAbs have been shown to bind to different sites like the CD4 binding site (CD4bs), the first and second variable regions (V1/V2), the glycan-V3 site on gp120 and the membrane-proximal external region (MPER) of the gp41 subunit. High potency bnAbs have been shown to provide robust protection against mucosal SHIV challenge in NHPs [25-27]. Drawback of these vaccines is that they do not effectively induce cellular immunity and also not mimic the natural route of infection.

\section{DNA vaccines}

DNA vaccines contain a plasmid with a few HIV genes encoding proteins of interest that are inserted into the backbone. The vaccine is administered into the recipient and HIV proteins are expressed. The proteins are broken down into peptides and presented on the surface of the cell for the immune system to respond. The DNA vaccines will deliver the genes without any immunity generated against the vector itself [28]. The most recent HVTN505 vaccine efficacy trial was a heterologous prime-boost strategy which evaluated a DNA vector expressing Gag, Pol, Nef, and Env as a prime and rAd5 vector expressed Gag, Pol, and Env as a booster (http://hvtn.org/505-announcement25April2013.html). No DNA vaccines have yet been accepted for use in humans. Disadvantages of these vaccines is that they are limited to protein immunogen only, extended immunostimulation leads to chronic inflammation

\section{Live vectors}

Genes of interest are inserted into the genomes of engineered virus to express the proteins inside the host. Viral vectors include non-disease causing viruses that are replication defective in mammalian cells or viruses that were engineered to be replication defective by deleting essential genes. Examples of viral vectors include canarypox virus vector used in the RV144 trial, recombinant adenoviral vector used in the step, Phambili and HVTN505 trials, New York Vaccinia virus strain (NYVAC) and Modified Vaccinia Ankara (MVA). In a new study using a Cytomegalovirus (CMV)-vector based vaccine in NHPs a strong control of viremia was demonstrated in vaccinated NHPs compared with those that received a DNA/rAd5 vaccine [29].
Genetic sequences that could encompass T-cell epitopes from global HIV-1 strains have also been created. These sequences called mosaic sequences constructed for insertion into viral vectors have been developed. This strategy is an attempt to tackle the problem of enormous diversity of HIV as an initial attempt to generate a global vaccine [30]. Adeno Associated virus (AAV), vectors with genes encoding for a bnAb against HIV-1 have been studied. This approach confers advantage of directly expressing broadly neutralizing IgGs, thereby avoiding the difficult process of eliciting bnAbs by the immune cells. A recent study has shown that injection of AAV vectors with inserts of genes encoding bnAbs into the muscles of humanized mice has conferred superior protection against high doses of intravenous HIV challenges [31]. The design and development of viral vectors has been the strongest of all other strategies used with some promising results.

\section{Peptide or protein vaccines}

This approach uses chemically synthesized protein subunits or peptides as vaccines to elicit cellular and humoral immune responses. The disadvantage is these vaccines require adjuvants to enhance the immunogenicity and currently alum is approved as the only adjuvant.

\section{Virus like-particles (VLPs)}

VLPs are look-alikes of infectious virions containing empty shells of the HIV envelope protein; they lack viral genome and are therefore non-pathogenic. As VLPs resemble the virus, they are capable of inducing high-level titers of bnAbs to protect against HIV which exhibit multivalent structures. VLPs do not require adjuvant to elicit robust antibody response as they are highly immunogenic themselves. Drawback of VLPs is that they stimulate strain-specific antibodies and induce an immune response against host cellular proteins, hence complicating the use of VLPs as antigens. It is also difficult to make these particles reproducibly.

\section{Discussion}

For the last two decades or so conventional vaccination methodologies have so far been unsuccessful in eliciting strong immune responses against HIV-1 and hence the field of HIV vaccine research has focused on many alternative vaccine strategies. It is imperative to note that a successful vaccine needs to elicit both $\mathrm{B}$ cell and $\mathrm{T}$ cell responses in order to be an effective preventive vaccine. Integrated research endeavors in designing and developing antigens that elicit broadly neutralizing antibody responses and protect against HIV infection, boosting up the $\mathrm{T}$ cell response to control viral replication and handling the problem of enormous HIV diversity are crucial elements in the pursuit of an HIV vaccine. Immune correlates of the modestly efficient RV144 trial have identified the V1V2 region to be the target of neutralizing antibodies and follow up studies are underway to evaluate multiple prime-boost regimens which will generate more data and insights in to the development of a vaccine. Recent discovery of bnAbs has provided a new and exciting avenue for designing an efficient vaccine. Unique approaches like B-cell lineage vaccine and AAV vector vaccines to elicit bnAb responses are being studied. By and large, this is a tremendously motivating period for HIV vaccine researchers, one that spawns more optimism markedly higher than in preceding years.

\section{References}

1. Amanna IJ, Messaoudi I, Slifka MK (2008) Protective immunity following vaccination: how is it defined? Hum Vaccin 4: 316-319.

2. Flynn NM, Forthal DN, Harro CD, Judson FN, Mayer KH, et al. (2005) Placebocontrolled phase 3 trial of a recombinant glycoprotein 120 vaccine to prevent HIV-1 infection. J Infect Dis 191: 654-665. 
Citation: Nageswara Rao A (2014) The Pursuit of a HIV Vaccine - Trials, Challenges and Strategies. J AIDS Clin Res 5: 298. doi:10.4172/21556113.1000298

3. Pitisuttithum P, Gilbert P, Gurwith M, Heyward W, Martin M, et al. (2006) Randomized, double-blind, placebo-controlled efficacy trial of a bivalent recombinant glycoprotein 120 HIV-1 vaccine among injection drug users in Bangkok, Thailand. J Infect Dis 194: 1661-1671.

4. Rerks-Ngarm S, Pitisuttithum P, Nitayaphan S, Kaewkungwal J, Chiu J, et al. (2009) Vaccination with ALVAC and AIDSVAX to prevent HIV-1 infection in Thailand. N Engl J Med 361: 2209-2220.

5. Corti D, Lanzavecchia A (2013) Broadly neutralizing antiviral antibodies. Annu Rev Immunol 31: 705-742.

6. Robertson M, Mehrotra D, Fitzgerald D, Duerr A, Casimiro D, et al. (2008) Efficacy Results from the STEP Study (Merck V520 Protocol 023/HVTN 502): A Phase II Test-of-Concept Trial of the MRKAd5 HIV-1 Gag/Pol/Nef Trivalent Vaccine.

7. Gray GE, Allen M, Moodie Z, Churchyard G, Bekker LG, et al. (2011) Safety and efficacy of the HVTN 503/Phambili study of a clade-B-based HIV-1 vaccine in South Africa: a double-blind, randomised, placebo-controlled test-of-concept phase $2 b$ study. Lancet Infect Dis 11: 507-515.

8. Watkins DI, Burton DR, Kallas EG, Moore JP, Koff WC (2008) Nonhuman primate models and the failure of the Merck HIV-1 vaccine in humans. Nat Med 14: 617-621

9. Priddy FH, Brown D, Kublin J, Monahan K, Wright DP, et al. (2008) Safety and immunogenicity of a replication-incompetent adenovirus type $5 \mathrm{HIV}-1$ clade B $\mathrm{gag} / \mathrm{pol} /$ nef vaccine in healthy adults. Clin Infect Dis 46: 1769-1781.

10. Excler JL, Rida W, Priddy F, Fast P, Koff W (2007) A strategy for accelerating the development of preventive AIDS vaccines. AIDS 21: 2259-2263.

11. Haynes BF, Gilbert PB, McElrath MJ, Zolla-Pazner S, Tomaras GD, et al. (2012) Immune-correlates analysis of an HIV-1 vaccine efficacy trial. N Engl J Med 366: 1275-1286.

12. Rolland M, Edlefsen PT, Larsen BB, Tovanabutra S, Sanders-Buell E, et al. (2012) Increased HIV-1 vaccine efficacy against viruses with genetic signatures in Env V2. Nature 490: 417-420.

13. Robb ML, Rerks-Ngarm S, Nitayaphan S, Pitisuttithum P, Kaewkungwal J, et al. (2012) Risk behaviour and time as covariates for efficacy of the HIV vaccine regimen ALVAC-HIV (VCP1521) and AIDSVAX B/E: a post-hoc analysis of the Thai phase 3 efficacy trial RV 144. Lancet Infect Dis 12: 531-537.

14. Zolla-Pazner S, deCamp A, Gilbert PB, Williams C, Yates NL, et al. (2014) Vaccine-induced IgG antibodies to V1V2 regions of multiple HIV-1 subtypes correlate with decreased risk of HIV-1 infection. PLoS One 9: e87572.

15. Schiffner T, Sattentau QJ, Dorrell L (2013) Development of prophylactic vaccines against HIV-1. Retrovirology 10: 72.

16. Stephenson KE, Barouch DH (2013) A global approach to HIV-1 vaccine development. Immunol Rev 254: 295-304.

17. Johnston MI, Fauci AS (2008) An HIV Vaccine-Challenges and Prospects. N Engl J Med 359: 888-890.
18. Girard MP Osmanov S, Assossou OM, Kieny MP (2011) Human immunodeficiency virus (HIV) immunopathogenesis and vaccine development: a review. Vaccine 29: 6191-6218.

19. Burton DR, Ahmed R, Barouch DH, Butera ST, Crotty S, et al. (2012)A Blueprint for HIV Vaccine Discovery. Cell Host Microbe 12: 396-407.

20. Kovacs JM, Nkolola JP, Peng H, Cheung A, Perry J, et al. (2012) HIV-1 envelope trimer elicits more potent neutralizing antibody responses than monomeric gp120. Proc Natl Acad Sci U S A 109: 12111-12116.

21. Walker LM, Huber M, Doores KJ, Falkowska E, Pejchal R, et al. (2011) Broad neutralization coverage of HIV by multiple highly potent antibodies. Nature 477 : 466-470.

22. Wu X, Yang ZY, Li Y, Hogerkorp CM, Schief WR, et al. (2010) Rational design of envelope identifies broadly neutralizing human monoclonal antibodies to HIV-1. Science 329: 856-861

23. Huang J, Ofek G, Laub L, Louder MK, Doria-Rose NA, et al. (2012) Broad and potent neutralization of HIV-1 by a gp41-specific human antibody. Nature 491 406-412.

24. Moldt B, Rakasz EG, Schultz N, Chan-Hui PY, Swiderek K, et al. (2012) Highly potent HIV-specific antibody neutralization in vitro translates into effective protection against mucosal SHIV challenge in vivo. Proc Natl Acad Sci U S A 109: 18921-18925.

25. Hessell AJ, Poignard P, Hunter M, Hangartner L, Tehrani DM, et al. (2009) Effective, low-titer antibody protection against low-dose repeated mucosal SHIV challenge in macaques. Nat Med 15: 951-954.

26. Hessell AJ, Rakasz EG, Tehrani DM, Huber M, Weisgrau KL, et al. (2010) Broadly neutralizing monoclonal antibodies 2F5 and 4E10 directed against the human immunodeficiency virus type $1 \mathrm{gp} 41$ membrane-proximal external region protect against mucosal challenge by simian-human immunodeficiency virus SHIVBa-L. J Virol 84: 1302-1313.

27. Donnelly J, Ulmer J, Shiver J, Liu M (1997) DNA vaccines. Annu Rev Immuno 15: $617-648$

28. Hansen SG, Ford JC, Lewis MS, Ventura AB, Hughes CM, et al. (2011) Profound early control of highly pathogenic SIV by an effector memory T-cell vaccine. Nature 473: 523-527.

29. Fischer W, Perkins S, Theiler J, Bhattacharya T, Yusim K, et al. (2007) Polyvalent vaccines for optimal coverage of potential T-cell epitopes in global HIV-1 variants. Nat Med 13: 100-106.

30. Balazs AB, Chen J, Hong CM, Rao DS, Yang L, et al. (2011) Antibody-based protection against HIV infection by vectored immunoprophylaxis. Nature 481 $81-84$

31. Eaton ML (2004) "VaxGen Fighting the AIDS Epidemic." Ethics and the Business of Bioscience. Stanford: Stanford University Press. 